NASA Contractor Report 189633

$p-29$

\title{
EXPERIMENTAL EVALUATION OF CANDIDATE GRAPHICAL MICROBURST ALERT DISPLAYS
}

Craig R. Wanke and R. John Hansman

\section{MASSACHUSETTS INSTITUTE OF TECHNOLOGY}

Cambridge, Massachusetts

\section{Purchase Order L-91172C}

June 1992

\section{N/Sก \\ National Aeronautics and \\ Space Administration}

Langley Research Center

Hamplon, Virginia 23665-5225

$$
\begin{aligned}
& \text { (NASA-CR-1B9333) EXPFRTMFNTAL EVALUATION OF } \\
& \text { CANDINATE GPAPHICAL MICRURURST ALFRT } \\
& \text { UISPLAYS Interim Annual Report (MIT) } 29 \mu \\
& 192-27424
\end{aligned}
$$





\begin{abstract}
A piloted flight simulator experiment has been conducted to evaluate issues related to the display of microburst alerts on electronic cockpit instrumentation. Issues addressed include display clarity, usefulness of multi-level microburst intensity information, and whether information from multiple sensors should be presented separately or "fused" into combined alerts. Nine active airline pilots of "glass-cockpit" aircraft participated in the study. Microburst alerts presented on a moving map display were found to be visually clear and useful to pilots. Also, multi-level intensity information coded by colors or patterns was found to be important for decision-making purposes. Pilot opinion was mixed on whether to "fuse" data from multiple sensors, and some resulting design tradeoffs have been identified. The positional information included in the graphical alert presentation was found useful by the pilots for planning lateral missed approach maneuvers, but may result in deviations which could interfere with normal airport operations. A number of flight crew training issues were also identified.
\end{abstract}

This work is being performed under Air Force Contract No. F19628-90-C-0002 and sponsored by the Flight Management Division of the NASA Langley Research Center. 


\section{Table of Contents}

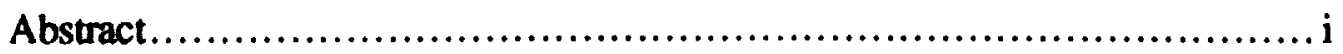

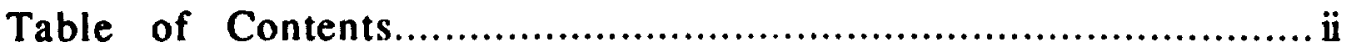

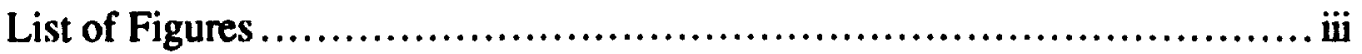

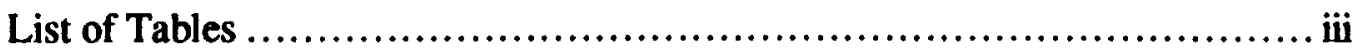

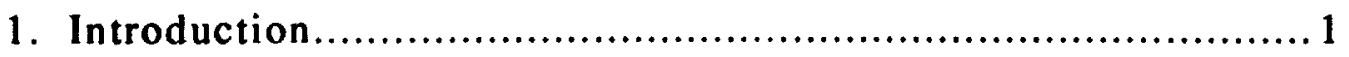

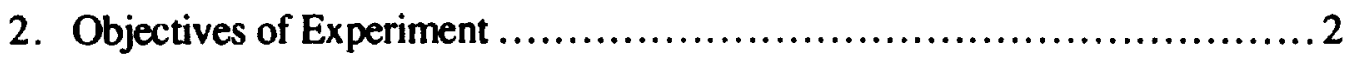

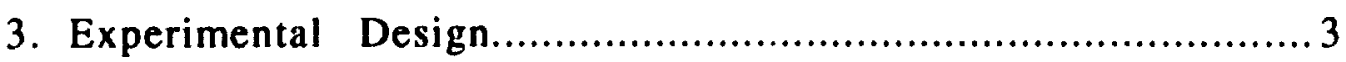

3.1 Overview .................................................... 3

3.2 MIT Advanced Cockpit Simulator............................. 3

3.3 Microburst Display Formats...................................... 5

3.4 Scenario Design..................................................... 10

3.5 Experimental Procedure............................................... 11

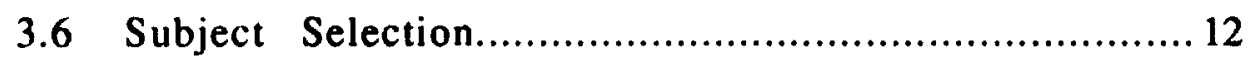

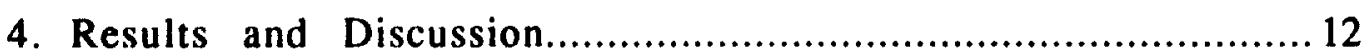

4.1 Visual Clarity of Alerts on EHSI ........................... 12

4.2 Overall Display Ratings................................... 12

4.3 Specific Display Features.................................. 13

4.4 Procedural Implications of Graphical Alerts.......................... 15

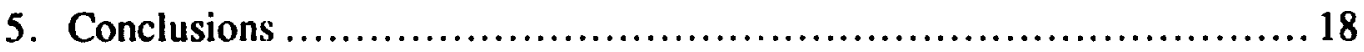

5.1 Display Format Issues ..................................... 18

5.2 Procedural Implications of Graphical Alerting ................... 19

5.3 Flight Crew Training Issues.......................................... 19

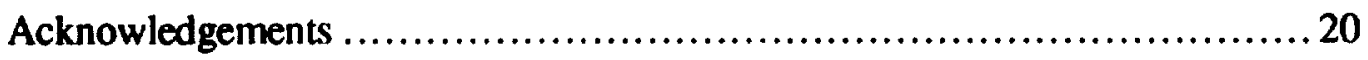

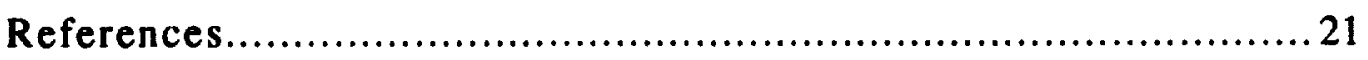

Appendix A: Exit Questionnaire ...................................... 22 


\section{List of Figures}

Figure 1. MIT Advanced Cockpit Simulator ............................. 4

Figure 2. Example of Display A on the EHSI...................................

Figure 3. Example of Display B on the EHSI................................... 8

Figure 4. Example of Display $C$ on the EHSI.......................................

Figure 5. Average pilot usefulness rankings for the three displays................ 13

Figure 6. Definition of decision distance. .............................. 15

\section{List of Tables}

Table 1. Microburst intensity levels for Display B ......................6 6

Table 2. Scenario characteristics.................................................. 11

Table 3. Pilot preference rankings for the three display types............... 12

Table 4. Subject rating of particular display features by need..................... 14 



\section{Introduction}

This report summarizes results of a piloted simulator study performed under the Cockpit Weather Information (CWI) program at MIT. This program is funded through the NASA Langley Research Center by the joint FAANASA Integrated Wind Shear program. The overall purpose of the NASA program is to reduce the wind shear hazard to transport-category aircraft through hazard characterization, development of airborne sensor technologies, and flight deck integration. The emphasis of current work at the MIT Department of Aeronautics and Astronautics is on integration of ground-based and airborne wind shear information to provide a crew-centered microburst hazard warning. This effort includes evaluation of candidate crew alerting procedures and investigation of methods for fusion of ground-based and airborne wind shear data.

In the past few years, systems for the detection of low altitude wind shear hazards, particularly microbursts, have been under steady development. These include ground-based systems such as Terminal Doppler Weather Radar (TDWR) and an enhanced version of the anemometer-based Low Level Windshear Alert System (LLWAS), as well as airborne forwardlooking systems such as infrared radiometers, doppler radar, and doppler lidar. In order to incorporate these new sensors into an effective alerting system, the problem of dissemination to flight crews must also be addressed. The variety of systems under development for both wind shear detection and ground-to-air datalink, combined with the advent of electronic cockpit instrumentation, allow many options for alert generation and dissemination.

A critical part of the dissemination task is the presentation of alerts to the flight crew in an easily understood and timely manner. A previous flight simulator study at MIT on this topic focussed on comparing verbal, alphanumeric, and graphical modes of presentation in the context of both ATC amendments and microburst alerts. This experiment ${ }^{1.2}$ demonstrated that graphical alerting is beneficial in terms of faster comprehension time, reduced crew workload, and increased crew situational awareness. Based on these results, a second simulator experiment was designed to evaluate specific format and implementation issues associated with graphical microburst alert displays, and to recommend an effective format based on the results. 


\section{Objectives of Experiment}

The experiment concentrated on displaying microburst alerts, assumed to be generated by ground-based and/or airborne remote detection systems, on an Electronic Horizontal Situation Indicator (EHSI). The EHSI is a navigational moving map display which lends itself to displaying positional threats such as microbursts. The issues addressed by the experiment ranged from display clarity to the procedural consequences of graphical alerts. They are summarized below:

1) Is it possible to add microburst alerts to the EHSI display during normal flight operation in a visually clear and understandable fashion, without creating visual "clutter"? The EHSI is used as a primary navigational instrument, and therefore already displays a large amount of information.

2) Should multiple levels of microburst intensity be displayed? The simplest display would show only "hazardous" microbursts, which have been selected through application of a suitable hazard criterion. Is this acceptable, or is it important to show multiple intensity levels, and if so, how many levels should be used?

3) In some situations, information will be available from multiple sources. For example, TDWR information could be uplinked to an aircraft which is equipped with a forwardlooking detection system of its own. Should measurements from all of the available sensors be combined to form a single "fused" alert, or should alerts from different sources be independently displayed?

4) Does lack of correlation between weather radar reflectivity and microburst alerts affect pilot confidence in the alerts? Microbursts can occur under conditions of heavy precipitation ("wet" microbursts) or very light precipitation ("dry" microbursts), and in either case, may or may not be correlated with the regions of highest weather radar reflectivity. This will be apparent with a graphical display, especially when weather radar returns are present on the same display.

5) What are the procedural implications of displaying graphical alerts? Graphical alerts contain detailed positional information, which is generally not true of verbal or alphanumeric alerts. Will a pilot who has not had experience with airborne wind shear sensors significantly alter his avoidance strategy when presented with graphical alerts? 
In this report, the term "alert" is used in general to indicate any microburst information which is presented to the flight crew for decision-making purposes. During the experiment, no pre-defined procedure for handling the information was prescribed to the pilots. This was done in order (1) to observe the pilots' perception of the situation severity as presented, and (2) to obtain the pilots' reactions and comments as an aid to design of proper procedures for graphical microburst alerting. It is recognized that in an operational system that there would be a distinction between microburst "alerting" information which would require mandatory flight crew action, and information which is "advisory" in nature. The criterion for distinguishing alerts from advisory information will be a function of microburst intensity, position, and possibly aircraft characteristics or configuration, and is a topic of current research.

\section{Experimental Design}

\subsection{Overview}

The experiment involved active airline pilots flying a series of realistic descent and final approach scenarios, under weather conditions conducive to wind shear, in a part-task "glasscockpit" transport-category aircraft simulator. The pilots flew similar situations with several different display formats, in order to evaluate the issues listed above. After the flight segment of the experiment, the pilots were asked to complete an exit questionnaire in order to obtain their opinions of the different display options. Additional data was obtained from observations and measurements made during the flight scenarios as well as from short debriefing sessions which took place between the scenarios.

\subsection{MIT Advanced Cockpit Simulator}

To perform this experiment, a part-task simulation of a modern transport aircraft equipped with an Electronic Flight Instrumentation System (EFIS) and a Flight Management Computer (FMC) was developed (Figure 1). It is an improved version of the simulation used in the presentation mode comparison experiment mentioned previously.1,2 The primary instrumentation is displayed on an IRIS 4D/25 color graphics workstation. The simulator includes a good fidelity representation of the EFIS displays, including the EHSI and the Electronic Attitude Director Indicator (EADI). Airspeed and altitude are displayed as moving tapes, and a vertical speed indicator is also included. The EHSI display is controlled through an external control panel which allows the pilot to change EHSI modes (MAP or ILS) and the display range, and to suppress unwanted information. 


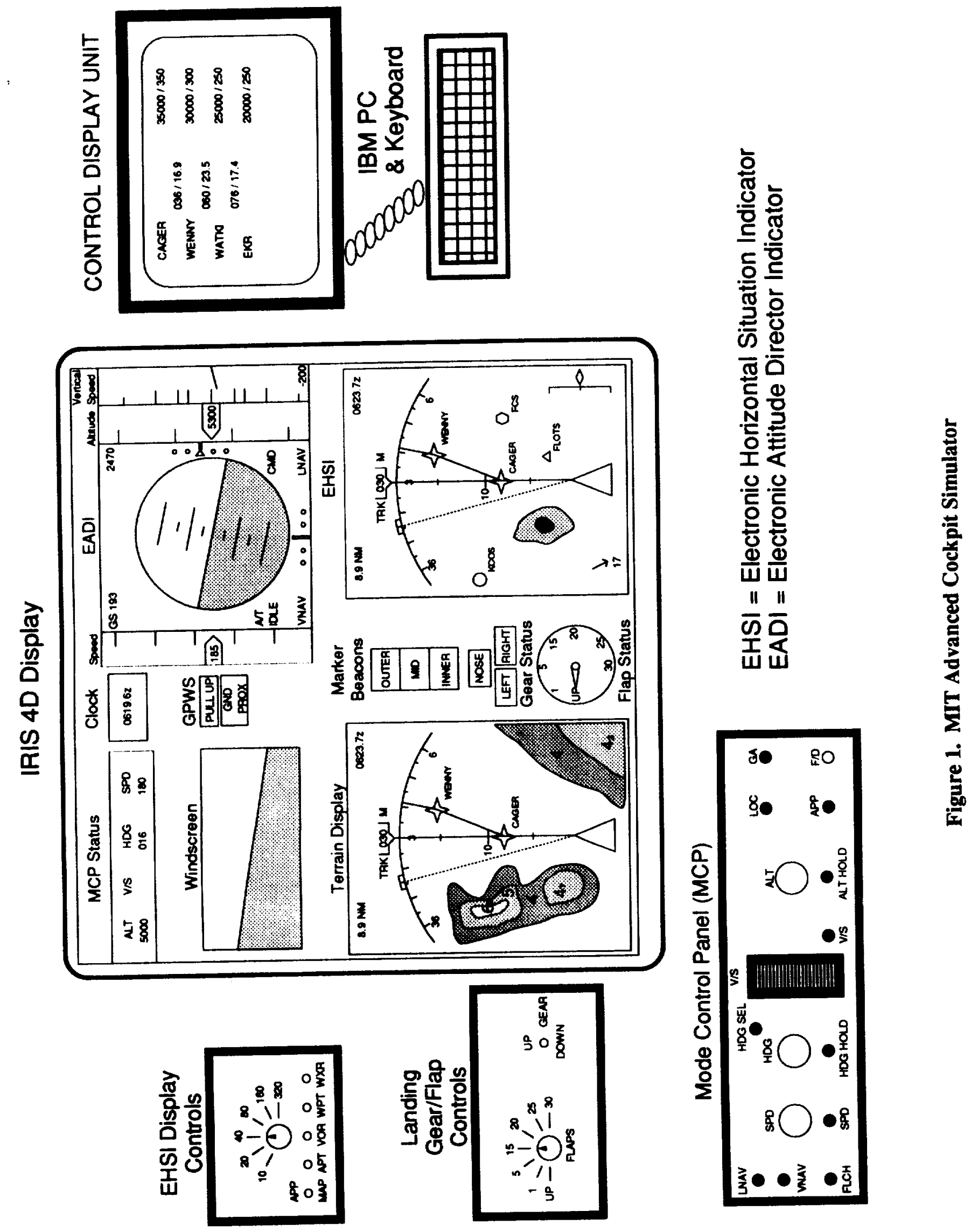


The Control Display Unit (CDU) for data entry into the FMC is simulated with an IBM/XT computer. It provides the necessary subset of the FMC functions required for the simulation. Non-FMC control of the aircraft is performed through an autopilot Mode Control Panel (MCP), similar to the one used on the Boeing 757/767. A standard set of autothrottle and autoflight modes are available, including LNAV/VNAV flight (i.e. following FMC-programmed lateral and vertical flight paths) and the various capture ("select") and hold modes for airspeed, heading, vertical speed, and altitude.

Graphical microburst alerts are presented on the EHSI display, which is the primary navigational instrument for this simulation. The EHSI also displays programmed route information, other airports, navaids, and waypoints, current track and heading information, distance and ETA to the next programmed waypoint, and weather radar reflectivity returns. The other large graphical display to the left of the EHSI is a prototype graphical terrain avoidance display, used in an experiment which ran concurrently with the microburst display experiment.

\subsection{Microburst Display Formats}

Three prototype microburst alert formats were designed to evaluate the issues listed above, by allowing pilots to fly similar scenarios with several different display features. Schematic views of the three displays are shown in Figures 2, 3, and 4.

Display A showed "fused" alerts based on a combination of all of the available sensor data, A single intensity threshold was applied in order to identify "hazardous" microbursts. These were then displayed as flashing solid red circles on the EHSI. The hazard threshold was based on the "F-factor" microburst hazard criterion" averaged over one-half mile; when this value exceeded 0.1 , an alert was issued. The F-factor criterion was used to set alert thresholds, rather than maximum velocity change as currently used in the TDWR system, because previous work has demonstrated that F-factor averaged over this distance correlates better with the impact of a microburst on an aircraft trajectory than maximum velocity change does. ${ }^{3}$

Display B was designed to evaluate the need for intensity information. It is a three-level display, also based on F-factor averaged over one-half nautical mile. A description of the level structure is given in Table 1. A level 1 microburst was displayed as a flashing hollow red circle, a level 2 microburst was displayed as a flashing solid red circle, and a level 3 microburst was

\footnotetext{
* F-factor is a hazard criterion, including both headwind loss and downdraft components, which indicates the instantaneous loss of aircraft available climb rate due to the immediate windfield. It is described in more detail in references 3,7 , and 8 .
} 
displayed as a flashing magenta/red crosshatched circle. In addition, the F-factor values were overlaid in white numerals, in order to generate pilot commentary about the use of numerical data on the display. Note that level 1 events as defined for this display would not be shown at all on displays $\mathrm{A}$ or $\mathrm{C}$, since the hazard value range falls below the "hazardous microburst" threshold (F $>0.1)$.

Table 1. Microburst intensity levels for Display B

\begin{tabular}{|c|c|c|}
\hline Intensity Level & F-Factor Range & Description \\
\hline 1 & $0.05 \leq \mathrm{F}<0.1$ & "low intensity" \\
2 & $0.1 \leq \mathrm{F}<0.15$ & "hazandous" \\
3 & $\mathrm{~F} \geq 0.15$ & "critically hazardous" \\
\hline
\end{tabular}

Display $C$ was designed to evaluate the need for knowledge of the source of the alerts, and specifically provided separate alert icons for ground-based and airborne forward-look wind shear sensors. Ground-based alerts were issued for F $>0.1$ and were displayed as flashing solid red circles. Regions of hazardous wind shear detected by airborne sensors (i.e. where F $>0.1$ ) were displayed as red/yellow crosshatched regions. The airborne sensor was assumed to have a maximum range of $5 \mathrm{~nm}$ and to scan $20^{\circ}$ to each side of the aircraft's flight path. In all cases, the airborne alerts and ground-based alerts were roughly consistent; the problem of receiving conflicting measurements from the different sensors was not addressed.

Of critical importance to this study was the explanation of the meaning of the F-factor hazard criterion to the pilot. This was done with reference to the three-level display (B). It was explained that F-factor measures the loss of effective thrust-to-weight ratio (and hence available climb rate) due to the windfield, and that a typical jet transport-category aircraft has a value of excess thrust-to-weight ratio of approximately 0.15 (varying with aircraft type and weight). It was then explained that a level 1 microburst would induce a loss of one-third to two-thirds of the aircraft's climb capability, a level 2 microburst would induce loss of two-thirds to all of the aircraft's climb capability, and a level 3 microburst would essentially compel the aircraft to descend. * These projected effects were based on a flight path directly through the center of the microburst icon.

\footnotetext{
* This explanation of F-factor was suggested by Dr. Roland Bowles and David Hinton of the NASA Langley Rescarch Center.
} 


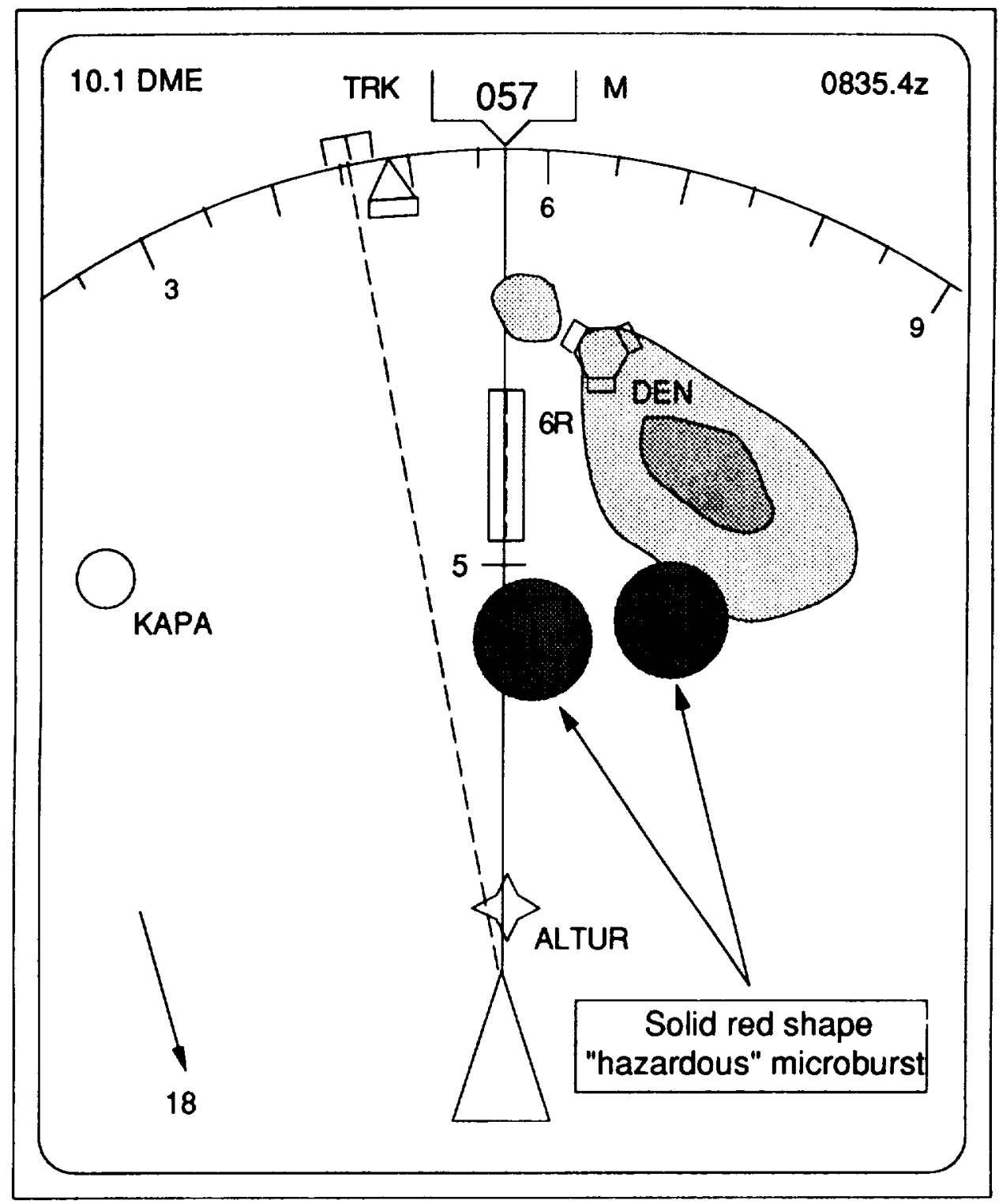

Figure 2. Example of Display $A$ on the EHSI. 


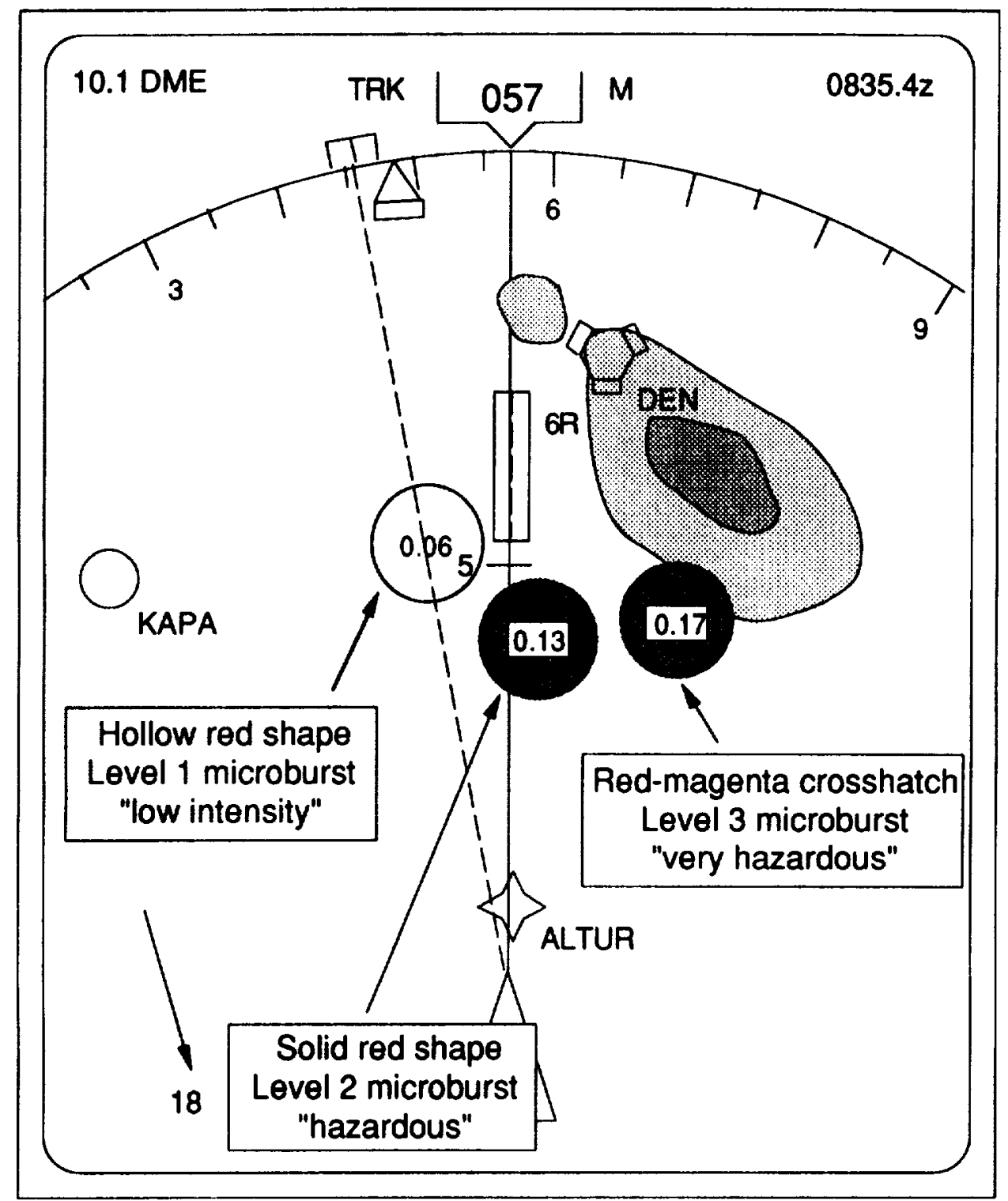

Figure 3. Example of Display $B$ on the EHSI. 


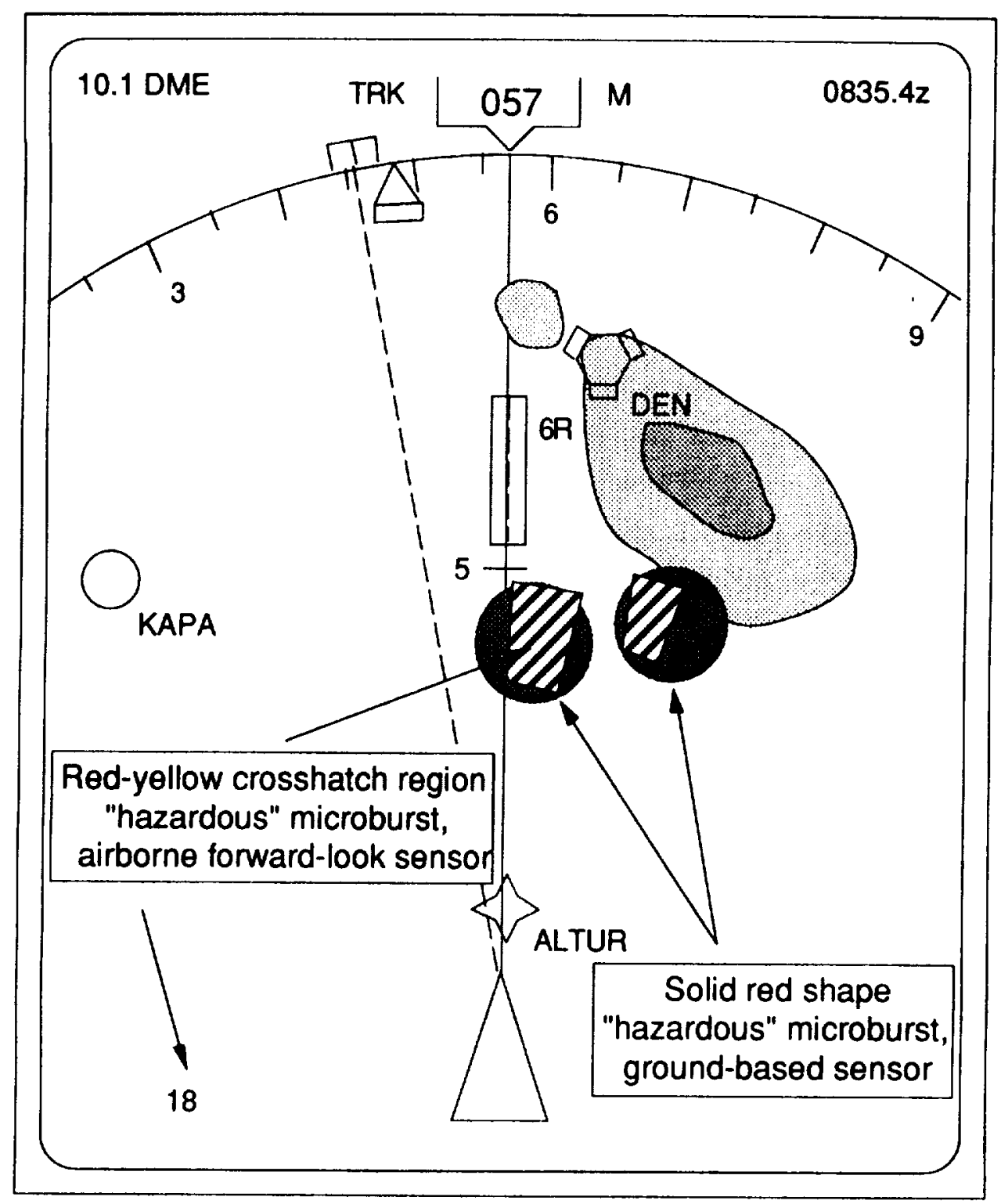

Figure 4. Example of Display $C$ on the EHSI. 


\subsection{Scenario Design}

A total of 12 approach scenarios were run with each pilot subject. These were chosen to evaluate the reaction of the pilot under differing conditions to the three displays, both quantitatively and qualitatively, and to stimulate commentary for the exit questionnaire. There were three independent variables in the experimental matrix:

1. Microburst display format $(\mathrm{A}, \mathrm{B}$, or $\mathrm{C})$

2. Presence/Absence of heavy precipitation ("wet" or "dry" microburst conditions)

3. Threatening situation (hazardous microburst present on approach path) or non-threatening situation (No hazardous microbursts within $1.5 \mathrm{~nm}$ of approach).

The precipitation (radar reflectivity) patterns for the "wet" and "dry" cases were chosen to be loosely representative of "typical" microburst events as described in the literature. ${ }^{4,5}$ In wet cases, thunderstorms were present in close proximity to the airport, with microbursts occurring either in the center or on the edge of high-reflectivity regions; in dry cases, only light precipitation was present in the vicinity of the airport.

The "threatening" and "non-threatening" cases were chosen to stimulate commentary on the operational use of the alerts. In the "threatening" case, hazardous microburst alerts (level 2 or 3 ) appeared directly on the flight path, and in the "non-threatening" case hazardous microburst alerts occurred at a lateral distance of 1.5 to $2 \mathrm{~nm}$ from the flight path. "Non-threatening" in this case does not presuppose that the pilot should make the approach if a microburst is present $1.5 \mathrm{~nm}$ laterally displaced from the flight path; it only indicates that, under the current TDWR alert methodology, no alert would be issued. ${ }^{6}$ In both cases, microburst icons began to appear when the aircraft approached to within 12-15 nm of the airport, and grew from level 1 to level 2 or 3 events before the aircraft reached the outer marker.

The nominal test Inatrix is shown in Table 2. Note that the effect of high vs. low precipitation was only tested using display A. Also, microbursts were present in only 8 of the 12 runs. In order to prevent anticipation, the microburst alert experiment was run in conjunction with a graphical terrain avoidance display experiment. In the cases where no microburst was present, terrain threats were present. The scenarios were carefully designed to prevent interference between the two experiments, and appeared to be effective in reducing pilot anticipation of both terrain and weather threats. The 12 scenarios were classified into three groups by display type, and the order of presentation of the blocks was alternated between subjects to attenuate learning effects. In each 
scenario, the aircraft was initially positioned between 25 and $50 \mathrm{~nm}$ from the airport, and was then vectored to an ILS approach. The scenarios averaged 10 to 15 minutes in length.

Table 2.Scenario characteristics. The order of the four blocks shown below was rotated between subjects to altenuale learning effects.

\begin{tabular}{|c|c|c|c|}
\hline Run \# & Display Type & WeyDry & Sccnario Type \\
\hline 1 & A & wet & no microbursts \\
2 & A & dry & non-threatening \\
3 & A & wet & threatening \\
\hline 4 & A & dry & threatening \\
5 & A & dry & no microbursts \\
6 & A & wet & non-threatening \\
\hline 7 & B & wet & non-threatening \\
8 & B & wet & no microbursts \\
9 & B & wet & thrcatening \\
\hline 10 & C & wet & threatening \\
11 & C & wel & non-threatening \\
12 & C & wet & no microbursts \\
\hline
\end{tabular}

\subsection{Experimental Procedure}

The experiment began with an explanation to the subject of the purpose of both the microburst alert and terrain depiction studies. This included a brief discussion of the state of the art in microburst detection and digital datalink, as well as the explanation of F-factor described in Section 3.3 above. The three display types were demonstrated and explained. Next, the pilot was given a practice run with the simulator to familiarize himself with the autopilot system, displays, and display controls.

The 12 scenarios were then run in two groups of 6 , with a break between the groups. At the beginning of each run, the pilot was provided with an approach plate and the ATIS ${ }^{*}$ message, and given as much time as needed to study them. During each run, one of the exp.rimenters acted as the air traffic controller, and communicated with the pilot via a wireless headset. The controls and displays were videotaped, and the appropriate numerical data was recorded in binary format by the simulation computer. After the 12 runs, an exit questionnaire (Appendix A) was conducted in order to obtain comments and numerical rankings of the displays and their features. The experiment required approximately 3 hours per subject to complete.

\footnotetext{
* The ATIS (Aulomalic Terminal Information Service) is a conlinuous radio broadcast of airport weather conditions and other non-control information in selected terminal areas.
} 


\subsection{Subject Selection}

All of the subjects for this experiment were active line pilots currently flying "glasscockpit" aircraft (Boeing 757-767, MD-88). Nine subjects participated, and all were males between the ages of 36 and 51 . Three of the pilots were captains, and six were first officers. The subjects averaged 5890 hours of total flight experience, and averaged 1130 hours of flight experience on EFIS/FMC-equipped aircraft.

\section{Results and Discussion}

\subsection{Visual Clarity of Alerts on EHSI}

The easiest issue to address was the visual clarity of the alerts when displayed on the EHSI. In the exit questionnaire, the pilots were asked to rate the three displays individually for visual clarity on a scale from 1 ("very difficult to read") to 4 ("very easy to read"). The results were almost identical for all three displays; all were rated easy or very easy to read, with average ratings between 3.5 and 4 . In the final approach situation, the pilots almost always set the EHSI to the minimum range $(5 \mathrm{~nm})$ with airports, navaids, and off-route waypoints suppressed, so the microburst alerts were by far the most prominent features on the display.

\subsection{Overall Display Ratings}

The numerical preference rankings from the survey give the best idea of the general acceptability of the three display formats. In this question, the subjects were asked to rank the three displays (A, B, and C) by order of preference from 1 (most preferable) to 3 (least preferable). The three level display (B) was ranked highest on average, followed by the discrete display (C) second, and display A last (Table 3). Although several of the pilots remarked on the need for simple and easy to comprehend displays, display A was never ranked the best. This may indicate that it does not contain enough information. Several pilots contended that they would like to see a display with both multiple intensity levels and information separated by source, although no suggestions about how this would be implemented were offered.

Table 3. Pilot preference rankings for the three display types. A ranking of 1 indicated most preferable, 3 indicatcd least preferable.

\begin{tabular}{|c|c|c|}
\hline $\begin{array}{c}\text { Display } \\
\text { Type }\end{array}$ & $\begin{array}{c}\text { Number of Times } \\
\text { Ranked First }\end{array}$ & $\begin{array}{c}\text { Average } \\
\text { Ranking }\end{array}$ \\
\hline A & 0 & 2.67 \\
B & 5 & 1.56 \\
C & 4 & 1.78 \\
\hline
\end{tabular}


Figure 5 shows the averaged responses to a question which asked the pilots to rank the three formats individually from 1 to 4 in terms of how useful they are to understanding the weather situation. A response of 1 indicated "not at all useful," while 4 indicated "very useful." The data indicates that display B was thought to be most useful, followed by display C. This is consistent with the overall preference ranking discussed above. It is also important to note that all of the average rankings exceeded 3 , which indicates that all of the displays were considered generally useful.

\subsection{Specific Display Features}

Three questions were also asked with regard to specific features of the displays (Table 4). These questions asked the subjects to rank the need for a particular feature, from 1 ("unnecessary") to 4 ("essential"). The concept of displaying three levels of intensity (as in display B) rather than the single level alert (as in display A) was strongly supported, with an average rating of 3.167. In all cases, this feature was rated between 3 and 4 . The numerical F-factor display feature was ranked significantly lower (2.222), and the large standard deviation indicates the large spread of responses on this question. Four of the subjects ranked this feature "unnecessary". A similar set of responses was received for the need to know the source of the information (display C). Again, although the average was near middle scale, the responses were strongly split between the ends of the scale. The reasons for the split responses on the latter two items were apparent from pilot comments, and will be discussed later.

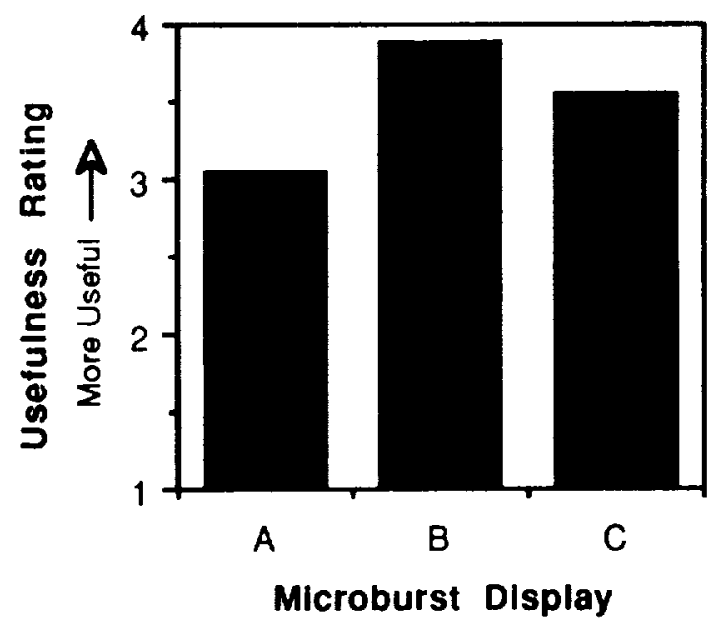

Figure 5. Average pilot usefulness rankings for the three displays 
Table 4. Subject rating of particular display features by need. The response scale used ran from 1 (unnecessary) to 4 (cssential).

\begin{tabular}{|l|c|c|}
\hline Display feature & Mean nced raling & Standard deviation \\
\hline 3-level intensity information (Display B) & 3.167 & 0.353 \\
Numerical F-factor information (Display B) & 2.222 & 1.202 \\
Different sensors displayed scparately (Display C) & 2.444 & 1.210 \\
\hline
\end{tabular}

All of the aforementioned data seem to indicate a preference for multiple levels of intensity. Pilot comments yielded some reasons for this. Several pilots remarked that having multiple intensity levels was important to their decision-making, since it implicitly provided some intensity trend information. With respect to this point, it should be noted that all of the scenarios did have microbursts which increased in intensity as the approach was made; that, however, is not an unrealistic situation. Another interesting observation was that the strength of the microbursts influenced how closely the pilot would approach the microburst. For example, a level 3 microburst located a given distance to one side of the approach track appears to be considered an equivalent threat (for decision-making purposes) to a level 2 microburst located closer to the approach track. The reasons for this were not clear from pilot comments; such a perception might be due to either lack of confidence in the position accuracy of the sensing system, or to the possibility that a microburst may move closer to the flight path. One of the subjects also stated that having multiple intensity levels made the alerts more compelling, and induced closer study of the situation (as compared to a single-level format).

There was no consensus on the use of numerical F-factor values, however. One pilot indicated that the numbers would be distracting, and that he didn't want to take the time to decipher that information; color-coded information is much easier to interpret. Another said that more levels might be desirable, but that the F-factor numbers required too much thought; perhaps a scale from 1 to 10 might be better. As stated above, a total of 4 subjects rated the F-factor numbers as unnecessary. However, several did rate them highly in terms of need, and one pilot actually preferred the numbers to the three-level intensity arrangement (due to the finer intensity resolution available). In general, the performance implication of the F-factor numbers was understood, and was found to be a good justification for the thresholds used in the alerting schemes, but no consensus was reached as to their usefulness in real-time situations.

The responses with regard to the "discrete" alert format used in Display C were also polarized. Several pilots reacted positively to the separated alerts due to the "reinforcing" aspect; they found it useful to know when the airborne sensor confirmed the ground-based report. In at least one case, the pilot stated that he would not need verbal confirmation of the alert from the 
tower if he saw that the airborne and ground-based sensors were reporting approximately the same information. This was borne out by his actions when flying the simulator. However, in the scenarios the ground-based and airborne sensor alerts were always reinforcing; in reality, this would not always be the case, and the effect of receiving contradictory alerts needs to be examined. Some of the other pilots indicated that dual information was not necessary, since if any sensor reported a microburst on or near the flight path, there would be no question of complying with the alert. Given this fact, they found knowledge of the alert source to be irrelevant. One pilot stated "if I saw one or the other alone, I would still have to assume that it was one hundred percent accurate."

\subsection{Procedural Implications of Graphical Alerts}

In the cases where a hazardous microburst was present directly on the approach track, it is interesting to examine the point in time where the pilot stopped monitoring the developing microburst situation and initiated a missed approach. The remaining distance between the aircraft and the nearest microburst icon on the approach track (Figure 6) was defined as the "decision distance". This distance was tabulated for all applicable cases (36 total runs), and had a mean value of $4.26 \mathrm{~nm}$ with a relatively low standard deviation of $1.15 \mathrm{~nm}$. This result is potentially

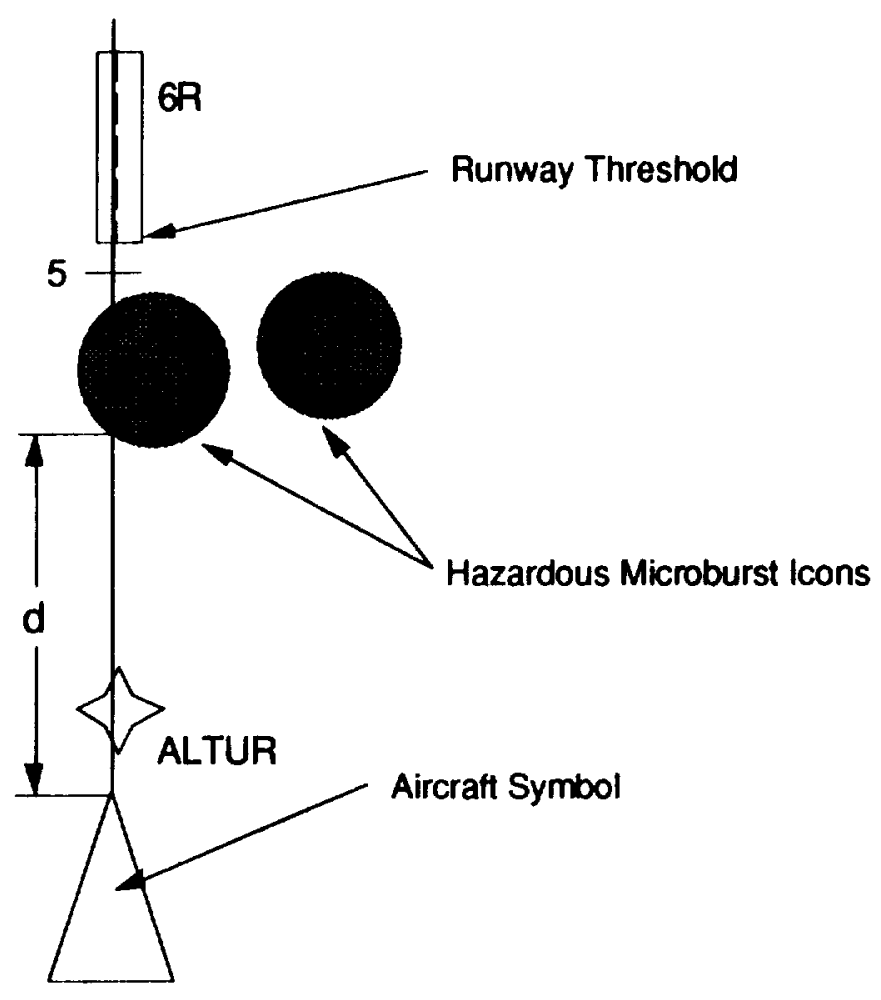

Figure 6. Definition of decision distance. The distance marked "d" (from the aircraft symbol to the nearest microburst icon on the approach track) at the time of go-around is referred to as "decision distance". 
useful for helping define crew response procedures for these alerts. It also emphasizes the importance of having a reliable ground-based detection and uplink capability, since most of the pilots made their decision at roughly the design limit range of some of the airborne sensors currently under development. ${ }^{7}$ It should be noted that, in this experiment, microbursts which occurred directly on the approach track were always located between 1 and 3 nautical miles from the runway threshold.

Several other implications of using graphical alerts were identified from experimental observations. One of these was the fact that the pilots typically asked for a turn when requesting a missed approach. In some cases, the pilot informed the tower well in advance (sometimes before the aircraft had reached the outer marker) which direction he would like to turn in the case of a missed approach. Several subjects indicated that positional information (which allowed this kind of missed approach planning) was the best feature of a graphical presentation.

The other side of this issue was that in none of the cases did the pilots seem to consider a straight-ahead missed approach as an option. In one case, a pilot requested a turn to avoid a microburst which took the aircraft directly through a high reflectivity thunderstorm core indicated by the weather radar. A straight ahead missed approach, since the aircraft was still several miles from the microburst, would have resulted in passage through the microburst region (where there was little precipitation indicated) at approximately 2000 feet AGL with a positive climb rate well established. The hazard involved in the straight ahead missed approach in this case was low, and probably less than that involved in making the turn into the storm. Another pilot commented that, if the controller insisted on a straight ahead missed approach which took the aircraft through the microburst alert, he (the pilot) would exercise his authority to make an emergency deviation. Behavior of this type could significantly impact airport operations. These events underline the need for training and for definition of a recommended set of procedures, since studies show that turns to avoid microbursts are not required given early initiation of a go-around. ${ }^{8}$

A connected issue relates to display of low intensity or less hazardous microburst alerts. Although none of the scenarios were explicitly designed to test this issue, it was apparent from several of the pilots' comments and actions that having a graphical alert of any magnitude on or very near the approach was grounds for a go-around. Some comments suggested that this was due to two possible reasons: 1) microbursts were observed to change in intensity fairly quickly, and 2) if anything is reported on the flight path, and the aircraft experiences any turbulence or wind shear or whatever, then the pilot may appear negligent for proceeding with the approach with an alert present. In view of this latter possibility, it is possible that any graphical alert no matter how low in intensity which is located on the approach or departure track will induce the pilot to abort, if not 
for safety than for legal reasons. In any case, it is apparent that the lowest alert threshold must be very carefully set in order to balance safety vs. operational efficiency, and that there is a need for established guidelines for reaction to forward-look airborne or uplinked ground-based wind shear alerts. It must also be considered that such behavior may have been an artifact of the simulation environment. This high level of caution is in sharp contrast to the verbal alerts issued during recent TDWR operational evaluations; low intensity "wind-shear-with-loss" alerts do not require that a missed approach be made, and pilots have been observed to continue approaches during microburst alerts of fairly high intensity.9.10

Since some of the scenarios forced the pilots to make a decision about microbursts which occurred 1.5 to $2 \mathrm{~nm}$ from the approach, it was possible to ask the question "how close can a hazardous microburst icon come to the approach path before you will decide not to make the approach?" The answers varied widely; six of the subjects were able to give a quantitative distance (based on a "hazardous" microburst alert as shown in display A). These ranged from $2 \mathrm{~nm}$ up to $15 \mathrm{~nm}$, with a mean of about $5 \mathrm{~nm}$; four of the six who answered this question gave distances of 2 and $3 \mathrm{~nm}$. In contrast, the current TDWR alerting methodology only gives an alert if some part of the microburst shape comes within one-half $\mathrm{nm}$ of the approach, and even with this criterion "nuisance alerts" occur. 19 This seems to imply that the positional information contained in the graphical alert could have a strong positive effect on pilot confidence in the alerting system. If the pilot makes an approach when a microburst alert is given 1 or $2 \mathrm{~nm}$ from the approach path, and experiences no wind shear, the graphical alert allows him to see that he has not actually penetrated the center of the microburst region. Under the current verbal alerting system, the pilot treats such a situation as a false alarm and may lose confidence in the alerting system; he or she has no way of knowing that the microburst does exist, but is displaced to one side of the approach.

One of the issues explicitly tested was the sensitivity of pilot decision-making to varying precipitation levels. No significant differences in pilot response were observed between "wet" and "dry" microburst situations. In one case, when microbursts appeared under very light rain conditions, a pilot commented that "that shouldn't be there," but in no cases did a pilot simply ignore an alert because of light precipitation. In reality, when "dry" microbursts are present, other visual clues (virga, dust rings, etc.) would likely be present which could not be simulated with the existing simulator facility. Several pilots did remark that they were more aware of and concerned about the wind shear threat under thunderstorm conditions. 


\section{Conclusions}

\subsection{Display Format Issues}

Several useful results were obtained with respect to the display format issues listed in Section 2. Overwhelmingly, the pilots found presentation of microburst alerts on the EHSI to be clear and effective. Also, use of multiple intensity levels was strongly supported, and several different reasons were given in pilot comments. These were: (1) a multiple-level presentation is more visually compelling than a single-level one, (2) simple intensity trend information is present in the multi-level presentation, and (3) "more caution" can be taken (i.e. maintain a larger distance from the event) when very intense microbursts are detected. It was apparent from experimental observations that the individual pilots had different ways of making decisions about the wind shear threats presented to them, and that the multi-level display seemed to allow them to more easily and confidently make those decisions. Based on these results, it is recommended that alerts should contain multiple intensity levels coded by icon colors or patterns rather than numbers.

Use of F-factor as an alert level threshold seems to work well. It relates closely to aircraft performance, and is thus a good indicator of the aviation hazard posed by a microburst; it was also easy to explain to the pilots in terms of loss in available climb performance. Determination of the actual values to be used for the alert thresholds requires further study.

The issue of whether to present "fused" or "discrete" microburst information was not completely resolved. Some pilots felt that there was absolutely no need to know where the alert comes from, because it would not change their actions to know how the microburst was detected. Others found it useful to know when the airborne sensor confirmed the ground-based report, and in one case the pilot indicated that he would not need verbal confirmation of the alert from the tower if both sensors were reporting the same information. In no cases did it seem critical to the pilot's decision making process to know where the alert was coming from, since it was assumed that all of the alerts issued were accurate. This would likely be assumed in practice as well, since microbursts can pose a strong threat. Thus, the improved accuracy available through data fusion must be weighed against the added confidence gained by the pilot when he is aware of reinforcing data from different sensors. This issue requires further consideration.

The effect of precipitation (radar reflectivity) on the believability of the microburst alerts was found in this experiment to be negligible. The pilots in all cases gave the microburst alerts $100 \%$ credence regardless of the intensity or proximity of the precipitation present. In an actual 
flight situation, this may be different because of the presence of external visual cues, particularly in "dry" microburst conditions.

\subsection{Procedural Implications of Graphical Alerting}

Several procedural implications of displaying graphical alerts were observed in this study. The positional information inherent in the graphical alert was well received by the pilots, and in almost all cases allowed them to plan and request a missed approach which took them clear of the event. Also, it was observed that the subjects made the decision to execute a missed approach when the aircraft was an average of $4.26 \mathrm{~nm}$ from the microburst. Another interesting observation was that the pilots were generally not willing to execute the approach when microburst icons were present within several miles of the approach track. This is inconsistent with the current TDWR alert methodology, in which microbursts which lie greater than one-half $\mathrm{nm}$ from the approach do not trigger any alerts. However, it is likely that knowledge of the location of the microburst would have a beneficial effect on pilot confidence in the alerting system. During recent TDWR evaluations, situations often occurred in which an alert was issued, but the aircraft did not actually encounter the microburst due to lateral displacement of the microburst from the flight path. The positional information contained in the graphical format would clarify this situation, and prevent the pilot from perceiving the alert as a false alarm.

\subsection{Flight Crew Training Issues}

Implementation of this system will require some pilot training in microburst meteorology, the impact of microbursts on aircraft performance, and the specific meaning of the alert structure which will be used. Several events which occurred during the experiment indicated that such training is required. For example, in none of the cases did the pilots seem to consider a straightahead missed approach as an option, even when the decision to abort the approach was made 5 to 10 $\mathrm{nm}$ from the microburst location. In one case, the pilot indicated that he would make an emergency deviation if the controller insisted on a straight-ahead missed approach. It needs to be emphasized that microbursts pose a danger primarily at low altitudes to slow-moving aircraft, and that a straight-ahead missed approach is acceptable if initiated early enough.

A related issue was raised by the lateral separation question, where the pilots were asked how close a microburst icon could be laterally to the approach path such that they would still make the approach (see Section 4.4). Responses of 2-3 nm are understandable, since the accuracy of the alert is to some degree unknown, and the possibility exists that other microbursts will appear in the same regions. Responses of $10 \mathrm{~nm}$ or $15 \mathrm{~nm}$ were also received; these most likely indicate that the 
pilot is unaware of the localized nature of microbursts. It should be again noted that the current TDWR alert methodology does not alert unless the microburst icon is within one-half $\mathrm{nm}$ of the approach path, and that the TDWR procedure has been criticized for alerting too often. For graphical alerts to be useful, lateral separation guidelines need to be established and included in flight crew training.

\section{Acknowledgements}

This work would not have been possible without the aid of many others. We would especially like to thank Gary Donovan of Delta Airlines and the Air Line Pilots' Association (ALPA), all of the helpful people at the Delta Master Executive Council of ALPA, and the pilots who volunteered their time to participate in these experiments. We would also like to thank Steven Campbell of MIT Lincoln Laboratory and David Hinton of the National Aeronautics and Space Administration (NASA), Langley Research Center, for their input, advice, and support. This work was supported by the MIT Lincoln Laboratory and the Flight Management Division of the NASA Langley Research Center under Air Force Contract No. F19628-90-C-0002. 


\section{References}

1. Wanke, C., and Hansman, R. J., "Hazard Evaluation and Operational Cockpit Display of Hazardous Windshear Information," AIAA Paper 90-0566, 28th Aerospace Sciences Meeting, Reno, NV, USA, January 8-11, 1990.

2. Wanke, C., Chandra, D., Hansman, R. J., and Bussolari, S. R., "A Comparison of Voice and Datalink for ATC Amendments and Hazardous Wind Shear Alerts," 4th International Symposium on Aviation and Space Safety, Toulouse, France, 20-22 November 1990.

3. Wanke, C., and Hansman, R. J., "Alert Generation and Cockpit Presentation for an Integrated Microburst Alerting System," AIAA Paper 91-0260, 29th Aerospace Sciences Meeting, Reno, NV, USA, January 7-10, 1991.

4. Wolfson, M. M., "Characteristics of Microbursts in the Continental United States," The Lincoln Laboratory Journal, Vol. 1, No. 1, pp 49-74, 1988.

5. Fujita, T. T., The Downburst: Microburst and Macroburst, The University of Chicago, 1985.

6. National Center for Atmospheric Research, "Tenninal Doppler Weather Radar (TDWR): A Briefing Paper," July 1, 1988.

7. Bowles, R. L., "Reducing Windshear Risk Through Airborne Systems Technology," 17th Congress of the International Council of the Aeronautical Sciences, Stockholm, Sweden, September 9-14, 1990.

8. Hinton, D. A., "Forward-Look Wind-Shear Detection for Microburst Recovery," Journal of Aircraft, Vol. 29, No. 1, Jan.-Feb. 1992.

9. Stevenson, Lloyd, Summary and Findings from the PIREP-Based Analyses Conducted During the 1988 to 1990 Evaluations of TDWR-Based and TDWR/LLWAS-Based Alert Senvices Provided to Landing/Departing Pilots, DOT/FAA Final Report DOT-VNTSC-FAA91-15, December 1991.

10. McCarthy, John, and Sand, Wayne, "Controller and Pilot Decision Making in Transmitting and Receiving Microburst Wind Shear Alerts from an Advanced Terminal Wind Shear Detection System," Preprints, ICAO Human Factors Seminar, Leningrad, U.S.S.R., April 3-7, 1990 . 


\section{Appendix A: Exit Questionnaire}

During this experiment, you were shown three different formats for possible display of microburst alerts on the EHSI. These three will be referred to as:

Display "A": Solid red circles indicate hazardous microbursts, alert information from all available sources has been integrated together.

Display "B": A three-level display with secondary events (hollow circles), hazardous events (solid red circles), and very intense events (red/magenta crosshatched circles). Quantitative intensity information (white text) was also included.

Display "C": Solid red circles indicate ground-measured hazardous microbursts, red/yellow cross-hatched areas indicate hazardous regions as measured by airborne look-ahead sensors.

1. Please rank the three display options in order of preference, 1 being highest and 3 being lowest:

\section{Display A \\ Display B \\ Display C}

Please comment on any exceptionally good or poor features of these displays:

2. Display $B$ differed from $A$ in that three levels of intensity information was available (i.e. not just "hazardous" or "not hazardous"). Please rank the importance of this intensity information:
1
2
3
4
unnecessary
essential

How does this intensity information affect your decision-making process? 
3. Another feature of display B was that of numerical "F-factor" hazard quantities overlaid on the microburst symbols in white text. Please rank the importance of this information:
1
2
3
4
unnecessary
essential

How does this information affect your decision-making process?

4. In display A, information from multiple windshear sensors was combined to form "fused" alerts. In display $\mathrm{C}$ information from different sensors was displayed individually (thus including the origin of the info) and the pilot must form a combined picture of the situation. Given that all sensors are equally reliable and accurate, would you say that knowledge of the origin of the information is:

$\begin{array}{cccc}1 & 2 & 3 & 4 \\ \text { unnecessary } & & & \text { essential }\end{array}$

How does knowing the origin of the information affect your decision-making process?

5. Microbursts have been known to occur both under conditions of heavy precipitation and under conditions of very light rain. How does the presence or non-presence of heavy precipitation affect your decision-making process in a microburst situation?

6. How far away from a hazardous microburst would you consider to be the "decision distance," i.e. how close will you get before you stop waiting for the situation to develop and decide whether or not to make a missed approach? 
7. Please rank the three display formats individually for visual clarity, i.e. how easy it was to pick the alert information out on the EHSI.

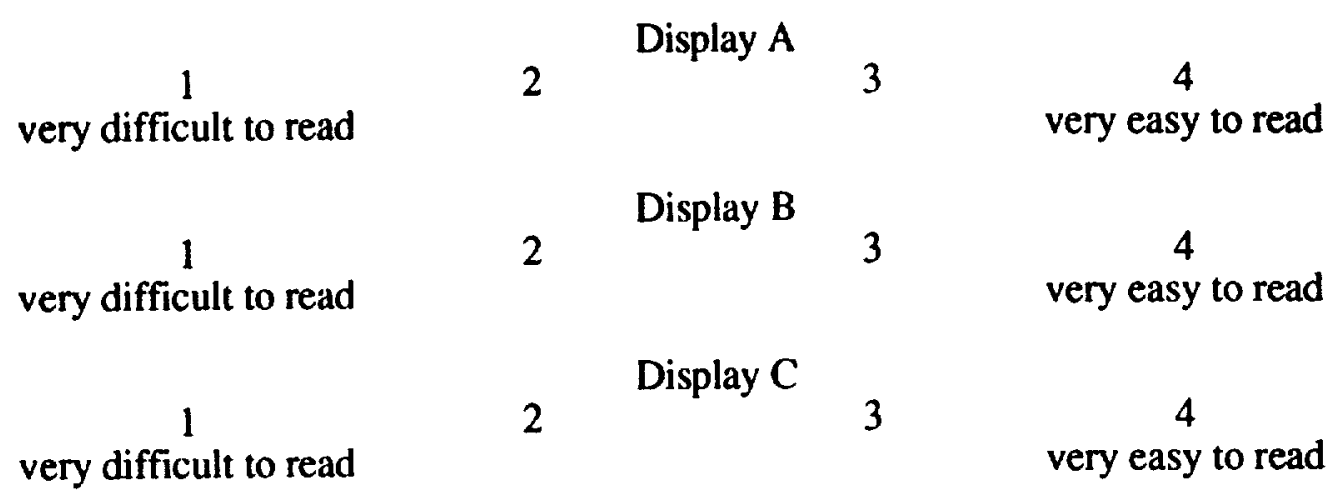

Comments:

8. Please rank the three display formats individually in terms of how useful they are to understanding the weather situation.

$\begin{array}{ccccc}\begin{array}{c}1 \\ \text { not at all useful }\end{array} & 2 & \text { Display A } & 3 & \begin{array}{c}4 \\ \text { very useful }\end{array} \\ \begin{array}{c}1 \\ \text { not at all useful }\end{array} & 2 & \text { Display B } & 3 & 4 \\ 1 & & & & \text { very useful } \\ \text { not at all useful } & 2 & \text { Display C } & 3 & 4 \\ & & & & \end{array}$

Comments: 



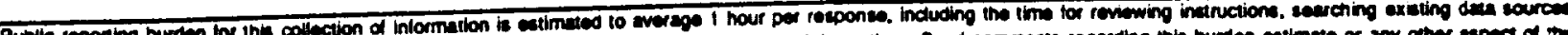

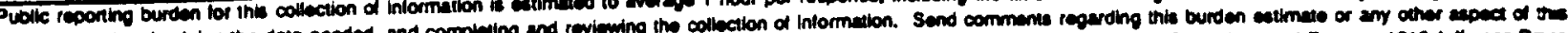

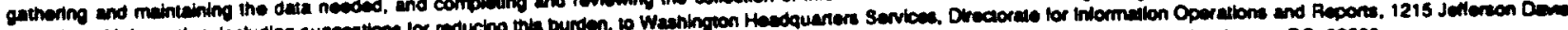

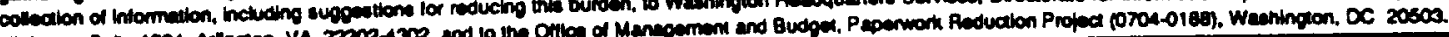

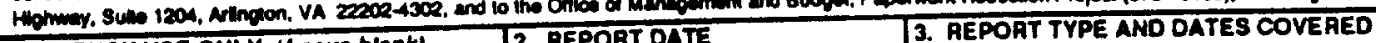

\begin{tabular}{|l|l|l} 
1. ACENCY USE ONLY (Lave blenk) & $\begin{array}{c}\text { 2. REPOAT DATE } \\
\text { June } 1992\end{array}$ & $\begin{array}{l}\text { 3. AEPOAT TYPE AND DATES CO } \\
\text { ContraCtor Report }\end{array}$
\end{tabular}

\begin{tabular}{|l|l|l|}
\hline 4. TTLE AND SUOTTLE & 5. FUNDINO NUMBEAS
\end{tabular}

Experimental Evaluation of Candidate Graphical Microburst Alert Displays

WU 505-64-12-01

L-91172C

6. AUTHOR(S)

Craig R. Wanke and R. John Hansman

7. PERFORMING OROANIZATION NAME(S) AND ADDAESS(ES)

8. PERFOAMING ORGAMIZATION

Aeronautical Systems Laboratory

Department of Aeronautics and Astronautics

REPORT NUMBEA

Massachusetts Institute of Technology

Cambridge, Massachusetts

9. SPONSORING / MONITORINO AGENCY NAME(S) AND ADDRESS(ES)

National Aeronautics and Space Administration

Langley Research Center

ASL-91-2

Hampton, VA 23665-5225

11. SUPPLEMENTARY NOTES I.A.A. Interim Annual Report

Langley Technical Monitor: David A. Hinton

Funded vis NASA Langley Purchase Order L-91172C under U.S. Air Force Contract No. F19628-90-C-0002.

12. OISTRIBUTION / AVALABILTY STATEMENT

Unclassified--Unlimited

Subject Category 06

13. ABSTAACT (Maximum 200 words)

A piloted flight simulator experiment has been conducted to evaluate issues related to the display of microburst alerts on electronic cockpit instrumentation. Issues addressed include display clarity, usefulness of multi-level microburst intensity information, and whether information from multiple sensors should be presented separately or "fused" into combined alerts. Nine active airline pilots of "glass-cockpit" aircraft participated in the study.

Microburst alerts presented on a moving map of display were found to be visually clear and useful to pilots. Also, multi-level intensity information coded by colors or patterns was found to be important for decision-making purposes. Pilot opinion was mixed on whether to "fuse" data from multiple sensors, and some resulting design tradeoffs have been identified. The positional information included in the graphical alert presentation was found useful by the pilots for planning lateral missed approach maneuvers, but may result in deviations which could interfere with normal airport operations. A number of flight crew training issues were also identified.

\begin{tabular}{|c|c|c|c|}
\hline \multicolumn{3}{|c|}{ 14. SUBJECT TERMS } & $\begin{array}{l}\text { 15. MUMBER OF PACES } \\
28\end{array}$ \\
\hline \multicolumn{3}{|c|}{$\begin{array}{l}\text { Microburst; Wind Shear; Cockpit Displays; Graphical Weather; Piloted } \\
\text { Simulation }\end{array}$} & $\begin{array}{l}\text { 16. PAICE CODE } \\
\mathrm{A03}\end{array}$ \\
\hline $\begin{array}{l}\text { 17. SECUATY CLASSIFICATION } \\
\text { OF REPORT } \\
\text { Unclassified }\end{array}$ & $\begin{array}{l}\text { 18. SECUATTY CLASSIFICATIOH } \\
\text { OF THIS PAOE } \\
\text { Unclassified }\end{array}$ & $\begin{array}{l}\text { 19. SECURITY CLASSIFICATION } \\
\text { OF ABSTRACT }\end{array}$ & 20. UMTATION OF ABSTRACT \\
\hline $7540-01-28$ & & & nderd Form 29 \\
\hline
\end{tabular}

